\title{
Conceptualism, Realism, and Intensional Logic
}

\author{
Nino B. Cocchiarella
}

\section{Introduction}

Linguists and philosophers are sometimes at odds in the semantical analysis of language. This is because linguists tend to assume that language must be semantically analyzed in terms of mental constructs, whereas philosophers tend to assume that only a platonic realm of intensional entities will suffice. The problem for the linguist in this conflict is how to explain the apparent realist posits we seem to be committed to in our use of language, and in particular in our use of infinitives, gerunds and other forms of nominalized predicates. The problem for the philosopher is the old and familiar one of how we can have knowledge of independently real abstract entities if all knowledge must ultimately be grounded in psychological states and processes. In the case of numbers, for example, this is the problem of how mathematical knowledge is possible. In the case of the intensional entities assumed in the semantical analysis of language, it is the problem of how knowledge of even our own native language is possible, and in particular of how we can think and talk to one another in all the ways that language makes possible.

I believe that the most natural framework in which this conflict is to be resolved and which is to serve as the semantical basis of natural language is an intensional logic that is based upon a conceptual analysis of predication in which what a predicate stands for in its role as a predicate is distinguished from what its nominalization denotes in its role as a singular term. Predicates in such a framework stand for concepts as cognitive capacities to characterize and relate objects in various ways, i.e., for dispositional cognitive structures that do not themselves have an individual nature, and which therefore cannot be the objects denoted by predicate nominalizations as abstract singular terms. The objects purportedly denoted by nominalized predicates, on the other hand, are intensional entities, e.g., properties and relations (and propositions in the case of 0-place predicates), that have their own abstract form of individuality, which, though real, is posited only through the concepts that predicates stand for in their role as predicates. That is, intensional objects are represented in this logic as concept-correlates, where the correlation is based on a logical projection of the content of the concepts whose correlates they are.

I have already described several such intensional logics in [2], [3] and [4], where the emphasis was on predicable concepts and their concept-correlates. I will review that account here to some extent, but my primary concern will be 
with the logic of referential concepts and the intensional objects that are their correlates. These objects, as we shall see, are also based on a logical projection of the content of the referential concepts whose correlates they are, but in this case the projection is through a double correlation, first of referential concepts with predicable concepts, and then of predicable concepts with their conceptcorrelates. As the products of such a projection of the content of referential concepts, these objects provide both a natural and a general solution of the problem of analyzing intensional discourse. They also provide a natural source from which to identify the objects of fiction, and of stories in general, since the latter will consist of propositions whose constituents are just such intensional objects (cf. [5]).

Before proceeding, however, there is an important distinction regarding the notion of a logical form that needs to be made when joining conceptualism and realism in this way. This is that logical forms can be perspicuous in either of two senses, one stronger than the other. The first is the usual sense that applies to all theories of logical form, conceptualist or otherwise; namely, that logical forms are perspicuous in the way they specify the truth conditions of assertions in terms of the recursive operations of logical syntax. In this sense, fully applied logical forms are said to be semantic structures in their own right. In the second and stronger sense, logical forms may be perspicuous not only in the way they specify the truth conditions of an assertion, but in the way they specify the cognitive structure of that assertion as well. To be perspicuous in this sense, a logical form must provide an appropriate representation of both the referential and the predicable concepts that underlie an assertion.

Our basic hypothesis in this regard will be that every basic assertion is the result of applying just one referential concept and one predicable concept, and that such an applied predicable concept is always fully intensionalized (in a sense to be explained). This will place certain constraints on the conditions for when a complex predicate expression is perspicuous in the stronger sensesuch as that a referential expression can occur in such a predicate expression only in its nominalized form. (A similar constraint will also apply to a defining or restricting relative clause of a referential expression.) In the cases where a relational predicable concept is applied, the assumption that there is still but one referential concept involved leads to the notion of a conjunctive referential concept, a notion that requires the introduction in intensional logic of special quantifiers that bind more than one individual variable. Except for briefly noting the need for their development, we shall not deal with conjunctive quantifiers in this essay.

\section{A Conceptual Analysis of Predication}

The form of conceptualism that I shall assume here is a holistic conceptualism in which impredicative concept formation is possible. This holistic conceptualism is not opposed to, but is rather based upon, a related form of constructive

conceptualism. The latter, as I have explained in [2] and [6], has affinities with 
nominalism, with which it is sometimes confused, because both validate only a predicative logic with a restricted form of comprehension principle. Holistic conceptualism has similar affinities with logical realism, with which it in turn is sometimes confused, because both validate an impredicative comprehension principle. Both the affinities and the differences between constructive conceptualism and nominalism, and between holistic conceptualism and logical realism, have already been described in [2]. These matters will not concern us here.

Nor will we be concerned with the difference between constructive and holistic conceptualism, which is of fundamental importance to the problem of how mathematical knowledge is possible (especially knowledge based on the concept of a limit or converging sequence of natural numbers). It is also important to issues regarding the stages of conceptual and linguistic development between pre-adolescence and post-adolescence (or the development of what Jean Piaget calls formal operational thought), but we shall ignore developmental issues here and assume that we are dealing with a mature or adult understanding of language in which impredicative concept formation is possible (such as the concept of a limit). The latter, as I have already noted in [2] and [6], is based not only on the stages of concept formation described in constructive conceptualism, but also on the capacity humans have for language. That is, impredicative concept formation is a mediated process, and language and the linguistic ability to use predicate expressions (as described in constructive conceptualism) is the means used to master and direct such a process.

Concepts in the sense intended here, accordingly, are neither predicate expressions nor independently real properties and relations, and among predicable concepts, some are impredicative in the sense that they involve or presuppose a totality to which they belong. Predicable concepts in particular, as already indicated, are cognitive capacities, or cognitive structures otherwise based upon such capacities, to characterize and relate objects in various ways. This means that they are not mental images or ideas in the sense of particular mental occurrences; nor are they individuals or saturated objects of any kind. Adopting Gottlob Frege's terminology, we shall speak of all concepts (of whatever kind) as being unsaturated, though different kinds of concepts, e.g., referential and predicable concepts, will be unsaturated in different but complementary ways.

Now as cognitive structures, concepts in the sense intended here are not Fregean concepts (which are independently real functions from objects to truth values in the case of first-level concepts, or from first-level concepts to truth values in the case of second-level concepts), even though they may be modeled by the latter to some extent. In particular, unlike Fregean concepts, the saturation (or exercise) of a concept in the sense intended here does not result in a truth value, but in a mental act, and, if expressed overtly, a speech act as well. In this regard, the unsaturatedness of a concept consists in its non-occurrent or purely dispositional status as a cognitive capacity that need not be exercised at any given time (or even ever, for that matter). Moreover, it is the exercise (or saturation) of such a capacity (as a cognitive structure) that informs particular mental acts with a predicable or referential nature. In addition, as intersubjectively realizable cognitive abilities that may be exercised by different persons 
at the same time, as well as by the same person at different times, concepts in the sense intended here are objective universals, even though they are not independently real properties and relations.

The two basic kinds of concepts that we shall be concerned with in this essay are referential concepts and predicable concepts. It is the exercise of a predicable concept, we have said, that informs a mental act (and, if expressed overtly, a speech act as well) with a predicable nature. Similarly, it is the exercise of a referential concept that informs the same act with a referential aspect. A categorical judgment, for example, is a mental act that consists in the joint application of both kinds of concept; that is, it is a mental event that is the result of the combination and mutual saturation of a referential concept with a predicable concept. Referential concepts accordingly have a type of structure that is complementary to that of predicable concepts in that each can combine with the other in a kind of mental chemistry that results in a mental act having both a referential aspect and a predicable nature. A general thesis that we shall maintain here is that every assertion (qua speech act) that is syntactically analyzable in terms of a noun phrase and a verb phrase (regardless of the complexity of either) is also semantically analyzable in terms of an overt application of a referential and a predicable concept, and that the assertion itself is the result of their mutual saturation in that joint overt application.

It should perhaps also be noted that intensional objects of the kind that we shall describe in this essay are in no sense to be understood as constituents of an assertion or of a mental act; nor are they constituents of any events at all for that matter. Rather, they are only logical projections on the level of individual objects of the contents of our predicable and referential concepts, where by the content of a concept we mean essentially the truth-conditions determined by the different possible applications of that concept.

In describing how this logical projection comes about, it must be kept in mind that predicable concepts are not independently real properties and relations, and, unlike referential concepts, their primary role in thought and communication is not referential but predicative. Yet, through a development of the interplay between language and thought, predicable concepts as cognitive capacities can be transformed into secondary or derived abilities that enable us to apply those concepts in a denotative manner corresponding to the use in natural language of nominalized predicates as abstract singular terms. It is through just such a secondary or derived application of a predicable concept, i.e., through a form of conceptual nominalization, that we project the existence of an intensional object, because what we purport to denote by such an application is a property or relation in the sense of an independently real platonic form. Thus, not only might we predicate of a building that it is rectangular, or of a person that he is wise by applying a predicable concept in each case, but, in addition, we also purport to denote the properties of rectangularity and wisdom, respectively, by applying those same concepts denotatively.

Purporting to denote and actually denoting are not the same thing, however, and despite all of our purportings there may in fact be no independently real properties and relations that are actually denoted by nominalized predicates. 
What I have called the Abelardian thesis in [2], [3] and [6] is in fact the claim that though different things may fall under the same concept, and in that sense have something in common, nevertheless a denotative application of that concept will always fail to denote anything at all.

As philosophical theories go, the Abelardian thesis may in fact be true. But it is not consonant with the view that is expressed in natural language and our common-sense framework in which most, if not all, of our purportings regarding the denotata of nominalized predicates are taken at face value; and it is that view that is our primary concern here. Thus, opposed to the Abelardian thesis as a conceptualist view is the alternative conceptualist view of conceptual realism, which in no way should be confused with logical realism. The problem of how we learn our native language if all knowledge must ultimately be grounded in psychological states and processes is not a problem but a project in conceptualism. And when intensional objects are acknowledged as real, abstract individuals, their role in the theory is always as concept-correlates; that is, our knowledge of such objects is only indirect and through the process of nominalization.

\subsection{Concept-Correlates and Frege's Double Correlation Thesis}

Intensional objects, I maintain, are concept-correlates; that is, they are real, abstract individuals that are somehow correlated with predicable concepts. Some intensional objects are also correlated with referential concepts; but that is because every referential concept uniquely determines some predicable concept, and it is as the correlate of such a predicable concept that an intensional object is also, indirectly, the correlate of a referential concept. It is these intensional objects that will be our primary concern in our discussion of referential concepts, and that we will identify as the real objects of the propositions toward which we might stand in various cognitive attitudes. Before taking up our discussion of these objects, however, we shall briefly review what I have said elsewhere about concept-correlates in general.

Let us note first that the important thing about concept-correlates is that our knowledge of them is only indirect and through the process of nominalization. This is because a semantical account of the role of a predicate's nominalization as an abstract singular term always presupposes a semantical account of the role of that same predicate as a predicate. This means in particular that any relational predicate such as 'exemplifies' or 'falls under', as in 'Socrates exemplifies humanity' and 'Bucephalus falls under the concept horse', is to be viewed as derived from an account of predication in which predicates do not have such nominalized forms, as in 'Socrates is human' and 'Bucephalus is a horse'. The latter sentences are conceptually prior to the former, in other words, as is clear from the psycholinguistic evidence on initial language acquisition. Indeed, for the conceptualist the priority of the role of a predicate as a predicate over the corresponding role of its nominalization as an abstract singular term is in fact one of the ways that we are to understand Frege's famous context principle. For 
it is only in the context of a sentence that a predicate can occur as a predicate, and it is primarily through a correlation with such occurences that we are to understand the role of a nominalized predicate as an abstract singular term.

Frege himself was not a conceptualist, or at least not in the sense intended here. Yet predicable concepts can be modeled, as we have indicated, by Frege's first-level concepts, and referential concepts can be similarly modeled by his second-level concepts. Note that the latter do not correspond to predicates the way that first-level concepts do, but to variable-binding operators that apply to wffs (well-formed formulas) and that result in wffs when so applied (such as the existential quantifier when affixed to an individual variable). (Equivalently, second-level concepts correspond to wffs with free predicate variables that can be used in a third-level comprehension principle to specify a variable-binding operator, such as the wff $(\forall x)[F(x) \rightarrow G(x)]$ for the second-level relation of subordination of one first-level concept to another.) Second-level concepts, in other words, are represented by variable-binding operators (or sentential contexts) in the scope of which a predicate occurs as a predicate. The first-level concept represented by such a predicate is then said by Frege to fall within the second-level concept represented by the operator in a sense similar to, but also different from, that in which an object is said by Frege to fall under that first-level concept.

Now the notion of a concept-correlate really has its origin in Frege, since all concepts for Frege were unsaturated functions (having truth values as their values) and therefore could not themselves be objects. In addition, as I have explained in [2], [3] and [4], the connection for Frege between a concept and its correlate is also based upon the priority of the semantical role of a predicate over that of its nominalization as an abstract singular term. This connection was expressed by Frege in what I have called his double-correlation thesis, that is to say, the thesis that corresponding to each second-level concept there is a special first-level concept such that a first-level concept, say, $G$, falls within that second-level concept if, and only if, the object correlated with $G$ (i.e., the object denoted by 'the concept $G$ ') falls under the corresponding first-level concept. Or in symbols (in the monadic case), where subject position occurrences of a predicate variable are nominalized occurrences of that variable:

$$
(\forall Q)(\exists F)(\forall G)[(Q x) G(x) \leftrightarrow F(G)] .
$$

Thus, for example, corresponding to the second-level concept of (objectual) existence, i.e., the second-level concept that existential quantifier phrases binding individual variables stand for, there is the special first-level concept of being realized; and, according to Frege, the correspondence is so tight that even the same proposition is expressed by, e.g., 'there is a square root of 4' and 'the concept square root of 4 is realized' (cf. [9], pp. 49f). A concept-correlate is realized, in other words, if, and only if, there exists an object that falls under the concept in question.

Concept-correlates for Frege, as I have explained in [3], are not what nominalized predicates purport to denote, namely intensional objects, but are rather 
value-ranges ( Wertverläufe), or classes (Begriffsumfangen) in the case of monadic predicates. This is because Frege was committed to an extensional logic in his analysis of mathematics, and, apparently, in his analysis of thought as well (cf. [10], p. 122). Conceptualism need not follow Frege in such a view, however, and I shall not assume that it does so here. Nevertheless, there is something important to conceptualism about Frege's view of value-ranges or classes as concept-correlates, namely that they are 'logical objects' that have their being not in the objects that belong to them but in the concepts whose extensions they are. This corresponds in conceptualism to the idea that our knowledge of intensional objects is only indirect and through the process of nominalization. For intensional objects are logical objects par excellence, and in conceptual realism we might well maintain that they are the only logical objects that there are, and that though they are real abstract individuals, nevertheless, at least in an epistemological sense, they have their being only in the concepts whose correlates they are.

Frege's double correlation thesis, in other words, as a thesis about the priority of the semantic role of predicates as predicates over that of their nominalizations as abstract singular terms, provides an ideal explanation in conceptualism of why our knowledge of intensional objects is only indirect and through the process of nominalization. For just as the double correlation thesis provides an explanation in Frege's extensional framework of how 'by means of our logical faculties we lay hold upon the extension of a concept, by starting out from the concept' ([10], p. 181), so too in conceptualism, where the thesis is about referential and predicable concepts and the intensional objects that are their correlates, it provides an explanation of how by means of our conceptual abilities we lay hold upon the intension of a concept, by starting out from the concept.

\section{Russell's Paradox in Conceptual Realism}

Frege's double-correlation thesis does more than provide an explanation in conceptualism of the epistemically derivative status of intensional objects. It also provides a solution to Russell's paradox. The solution, it turns out, allows for a reconstruction of Russell's early (pre-1905) form of logicism, as well as two alternative reconstructions of Frege's form of logicism (cf. [3]). As might be expected, given Frege's distinction between concepts and concept-correlates and the way that predicable and referential concepts can be modeled by Frege's first-and second-level concepts, one of the reconstructions of Frege's system can be developed as an intensional logic for conceptual realism.

Now what is noteworthy about the logico-grammatical context of both Frege's and Russell's early form of logicism is that it contains the essentials of what constitutes a theory of logical form. These are (1) the basic forms of predication that underlie any possible assertion we might make in language, (2) sentential connectives for the formation of compound wffs, (3) quantifier expressions that reach into predicate as well as subject positions (just as they do in natural language), and last, but not least, (4) nominalized predicates (and propositional 
forms) as abstract singular terms. Frege and Russell did not interpret these essentials in the same way, their most important difference, as I have explained in [3], being in what each took nominalized predicates to denote. In particular, for Russell a nominalized predicate denoted as a singular term the same independently real property or relation that the predicate otherwise expressed in its role as a predicate. For Frege, as we know, the distinction between what a predicate stands for and what its nominalization denotes as an abstract singular term is fundamental, just as it is in conceptual realism - except that for Frege what a predicate stands for is not a cognitive capacity but an independently real function from objects to truth values.

In describing the logical grammar that is in question here, we shall adopt the traditional practice of marking the nominalization of a predicate by deleting the argument or subject positions that come with it in its role as a predicate, i.e., by deleting the parentheses (and commas in the case of a relational predicate) that precede and succeed (or separate in the case of commas) the singular terms to which the predicate can be applied. Thus, for example, whereas $F(x)$ and $R(x, y)$ are wffs in which $F$ and $R$ occur as predicates, $G(F)$ and $G(R)$ are wffs in which $F$ and $R$ occur as singular terms. In $F(F)$ and $R(F, R), F$ and $R$ occur both as predicates and as singular terms (though no single occurrence can be both as a predicate and as a singular term).

In addition to simple predicates, we also need a device for constructing complex predicates. Instead of Frege's smooth-breathing abstraction operator or Russell's circumflex operator, we shall use Church's $\lambda$-operator for this purpose. Thus where $\varphi$ is a wff, we will also have $[\lambda x \varphi]()$ and $\left[\lambda x_{1} \ldots x_{n} \varphi\right](, \ldots$,$) as$ complex 1-place and $n$-place predicates (note the accompanying pair of parentheses and commas) and $[\lambda x \varphi]$ and $\left[\lambda x_{1} \ldots x_{n} \varphi\right]$ as complex singular terms (in which the parentheses and commas that come with the predicates have been deleted). For convenience, we shall usually drop the accompanying parentheses and commas when referring to predicates (as we did in the preceding paragraph), though always, whenever a predicate occurs in a wff as a predicate it will have an accompanying pair of parentheses (and commas as well if it is a relational predicate).

As individual variables, we shall use ' $x$ ', ' $y$ ', and ' $z$ ', with or without a numerical subscript, and as $n$-place predicate variables we shall use ' $F$ ', ' $G$ ', and ' $R^{n}$ '. (We will usually drop the superscript when the context makes clear the degree of a predicate variable, or when it does not matter what degree it is.) Propositional variables, it should be noted, are assumed here to be 0-place predicate variables. Note that where $n=0,\left[\lambda x_{1} \ldots x_{n} \varphi\right]$ is just $[\lambda \varphi]$, which we shall abbreviate as $[\varphi]$ and read as 'that $\varphi$ ' when it occurs as an abstract singular term, i.e., as a nominalized propositional form. Finally, as logical constants, we shall use $\wedge, \vee, \rightarrow, \leftrightarrow, \neg, \square, \diamond,=, \forall, \exists$ and $\lambda$ with their usual readings. For convenience, we ignore going into the formal details of defining the different types of meaningful expressions here (but refer the reader who wants such details to [2], chapter V or [3], §7).

Our inclusion of the modal operators $\square$ and $\diamond$ for necessity and possibility may seem to conflict with Frege's extensional view of logic, but actually, were 
we to assume Frege's principle of extensionality, i.e., his basic law (Va),

$$
\left(\forall x_{1}\right) \ldots\left(\forall x_{n}\right)(\varphi \leftrightarrow \psi) \rightarrow\left[\lambda x_{1} \ldots x_{n} \varphi\right]=\left[\lambda x_{1} \ldots x_{n} \psi\right],
$$

what would follow in a reconstruction of his framework is only the redundancy of $\square$ and $\diamond$ as formula operators. That is, $(\square \varphi \leftrightarrow \varphi)$ and $(\nabla \varphi \leftrightarrow \varphi)$ would then be provable, in which case both operators could be read simply as 'it is the case that'. Of course we shall not assume (Ext*) in our development of conceptual realism; nor, for that matter, will we assume its intensional counterpart,

$$
\square\left(\forall x_{1}\right) \ldots\left(\forall x_{n}\right)(\varphi \leftrightarrow \psi) \rightarrow\left[\lambda x_{1} \ldots x_{n} \varphi\right]=\left[\lambda x_{1} \ldots x_{n} \psi\right] .
$$

(In general, we use a ${ }^{*}$-label as a reminder that the theses we consider deal with wffs that contain nominalized predicates as abstract singular terms.) Our inclusion of the modal operators here, in other words, is primarily so as to make clear what is not being assumed in our development of conceptual realism. (The modal operators have other uses in conceptual realism that we shall not go into in the present essay.) For the purposes of conceptualism itself, incidentally, we should also include the tense operators that are needed to represent the cognitive schemata characterizing our conceptual orientation in time and that are implicit in the form and content of our assertions as mental acts. These additions, however, along with others yet to be specified, will be left to our general understanding of how the present grammatical framework is to be extended in its application to conceptual realism.

Now in regard to Russell's paradox, let us note that a fundamental assumption of the logistic context in which this paradox was originally formulated is the unrestricted comprehension principle,

$$
\left(\exists F^{n}\right)\left(\left[\lambda x_{1} \ldots x_{n} \varphi\right]=F\right)
$$

where $\varphi$ is a wff in which $F^{n}$ does not have a free occurrence. No paradox is forthcoming, it should be noted, if no nominalized predicate occurs in $\varphi$ as an abstract singular term, i.e., if $\varphi$ is a wff of standard second-order predicate logic. Russell's paradox, in particular, requires the use of a nominalized predicate in the following instance of $\left(\mathrm{CP}_{\lambda}^{*}\right)$ :

$$
(\exists F)([\lambda x(\exists G)(x=G \wedge \neg G(x))]=F) .
$$

One way to avoid Russell's paradox, accordingly, at least from the point of view of Russell's and Frege's logical realism, is to restrict $\left(\mathrm{CP}^{*}\right)$ so as to exclude certain wffs $\varphi$ in which nominalized predicates occur. This would leave intact all of standard second-order predicate logic, and in that regard most of the predicates of natural language that we want to represent. The restriction would be justified in the context of Russell's and Frege's logical realism in that what $\left(\mathrm{CP}^{*}\right)$ posits in such a context are independently real properties and relations, and what Russell's paradox shows is that we must put some constraints on how we posit such entities. The problem, however, is how to decide in a principled way which wffs are to be excluded from $\left(\mathrm{CP}_{\lambda}^{*}\right)$ and which are not. Excluding 
all wffs that contain nominalized predicates would do, but that would lead to a rather impoverished version of logical realism that no longer has the naturalness or the power of the original framework. And excluding wffs only in an ad hoc manner, i.e., once it is discovered that they lead to a contradiction, would result in a non-effective comprehension principle, i.e., one for which it cannot be effectively decided what is and what is not an instance of that principle. What is needed, in other words, is an effective rule by which to decide which wffs are to be excluded and which not, and one, moreover, that leaves the bulk of the original framework essentially intact. For the purpose of conceptual realism, as opposed to Russell's and Frege's logical realism, it would also be appropriate if such a rule had a natural explanation in conceptualist terms, i.e., in terms that were directly based on the conceptual process of nominalization.

Now Frege's double correlation thesis, as I have explained in [3], provides the basis for just such a rule. Thus, in the context of Frege's form of logicism, the idea is that if, in accordance with the thesis, second-level concepts can be correlated with first-level concepts, then third-level concepts, i.e., concepts within which second-level concepts fall, can be similarly correlated with secondlevel concepts, and therefore by the product of these correlations, third-level concepts can be correlated with first-level concepts. Similarly, fourth-level concepts can be correlated with third-level concepts and therefore with first-level concepts as well. In general, in other words, all concepts of whatever level can be correlated with, and in effect be represented by, first-level concepts and the concept-correlates that fall under them.

But if all higher-level concepts can be correlated in a telescoping manner with first-level concepts, then a natural constraint on the conditions for specifying a first-level concept under which concept-correlates fall, i.e., for restricting instances of $\left(\mathrm{CP}_{\lambda}^{*}\right)$ in which the comprehending wff contains occurrences of nominalized predicates, is that these conditions are to be stratified in a way corresponding to the stratification of the different levels of concepts that are being telescoped and represented in that first-level concept. That is, the effective rule for restricting the comprehension principle $\left(\mathrm{CP}_{\lambda}^{*}\right)$ is that it should apply only to wffs whose component predications can be stratified. More precisely, for reasons explained in [2] and [3], the $\lambda$-abstracts that are to be allowed in instances of $\left(\mathrm{CP}_{\lambda}^{*}\right)$ must all be homogeneously stratified (cf. [2], p. 217, [4], $§ 4$ or [3], $\S 9$ for the definition of homogeneous stratification). Accordingly, since we are assuming that every ( $n$-place) predicate expression stands for a predicable concept, i.e., for a value of the bound ( $n$-place) predicate variables, this means that any $\lambda$-abstract that is not homogeneously stratified must be excluded as not being grammatically well-formed. The resulting logic, which is obtained by simply extending the laws of standard second-order predicate logic so as to apply to wffs with, as well as wffs without, nominalized predicates as abstract singular terms, is easily seen to be equiconsistent with the theory of homogeneous simple types; and for that reason it is called, $\lambda \mathrm{HST}^{*}$, or $\square \lambda \mathrm{HST}^{*}$ when it is extended to include the axioms and rules of the S5 modal propositional logic as well.

$\checkmark \lambda \mathrm{HST}^{*}$ is not itself a type theory, it should be emphasized, but is a second- 
order predicate logic with nominalized predicates as abstract singular terms, i.e., with nominalized predicates as legitimate substituends of the bound individual variables. In this regard, $\square \lambda \mathrm{HST}^{*}$ retains all of the natural features of the framework that Frege and Russell originally had in common in their respective versions of logicism at the turn of the century; and, except for the exclusion of inhomogeneously stratified $\lambda$-abstracts, it seems to retain all of the power of expression of that framework as well. Of course, as the basis for a logical reconstruction of either Frege's or Russell's early form of logicism, certain axioms will still need to be added to $\square \lambda$ HST $^{*}$, such as (Ext*) for Frege's system and perhaps ( $\square$ Ext*) for Russell's, along with a certain principle of rigidity (for Russell's 'no-classes' theory) that reduces classes to those properties that have the same extension in every possible world. These are not matters that concern us here, however (but see [3] for details). For besides being the basis of a logical reconstruction of either Frege's or Russell's early form of logicism, $\square \lambda$ HST $^{*}$ is also the basis for the development of an intensional logic for conceptual realism, and it is this development that is our concern in this essay.

First, let us note that from the point of view of conceptual realism, the collapsing and telescoping of Frege's hierarchy of concepts into the level of firstlevel concepts and their concept-correlates explains why in fact we do not have expressions in natural language for anything like Frege's third- and higher-level concepts, i.e., why the only concepts we normally construct corresponding to those of Frege's hierarchy are the predicable and referential concepts we exercise in thought and speech. For it is not that natural language expressions for socalled higher-level concepts cannot in principle be constructed, such as, e.g., third-level quantifiers binding variables for referential (quantifier) expressions. Rather, even aside from their complexity and inelegance, such expressions are completely superfluous. That is, we do not need such expressions because we can already say by means of the expressions that we construct for predicable and referential concepts, and the intensional objects that are their conceptcorrelates, all that we could ever say with the so-called third- and higher-level concepts that they would stand for. And that we can do this is what Frege's double correlation thesis enables us to explain in conceptual realism.

It is not the case, however, that $\square \lambda \mathrm{HST}^{*}$ gives the best way of expressing Frege's double correlation thesis in the context of conceptual realism. For unlike the situation in Frege's and Russell's versions of logical realism, what predicates stand for in conceptual realism are concepts in the sense of cognitive capacities and not independently real properties and relations (or functions from objects to truth values). In that regard, the exclusion of inhomogeneously stratified $\lambda$-abstracts from the class of grammatically well-formed predicate expressions seems inappropriate and counter-intuitive. After all, how could Russell even have formulated his paradox if we could not form a concept, to begin with, corresponding to the predicate $[\lambda x(\exists G)(x=G \wedge \neg G(x))]$ ? It is one thing to maintain that certain predicates, when nominalized, have no independently real property or relation corresponding to them, but quite another to claim that we cannot form the concepts that these predicates otherwise stand for in their role as predicates. As a description of the laws of compositionality for concept- 
formation, in other words, as opposed to the laws for positing independently real properties and relations, we should allow no restrictions to be imposed on the comprehension principle $\left(\mathrm{CP}_{\lambda}^{*}\right)$. But then how, in the context of conceptual realism, are we to avoid Russell's paradox?

The answer is implicit in what we have just said regarding the difference between the laws of compositionality for concept-formation and the laws for positing independently real properties and relations; namely, that whereas the one set of laws pertains to the role of predicates as predicates, the other pertains to the role of their nominalizations as abstract singular terms. The solution, in other words, is that we cannot impose on reality the demand that to whatever concept we can form there must always be an independently real property or relation that is that concept's correlate. Some concepts are such that they allow for no logical projection on the individual level of their intensional content, i.e., of the truth conditions that are determined by their different possible applications.

Logically, what this solution comes to is allowing that some singular terms, and certain nominalized predicates in particular, must be denotationless. That is, we must adopt a logic that is free of existential presuppositions regarding singular terms. ${ }^{1}$ Leaving $\left(\mathrm{CP}_{\lambda}^{*}\right)$ and the laws of second-order predicate logic otherwise intact, i.e., otherwise than replacing its first-order component by one that is free of existential presuppositions for singular terms, note that although $\left(\mathrm{CP}_{\lambda}^{*}\right)$ posits the existence of a concept that we can form corresponding to $[\lambda x(\exists G)(x=G \wedge \neg G(x))]$ as a predicate, nevertheless, by Russell's argument, it is provable that there can be no object corresponding to $[\lambda x(\exists G)(x=G \wedge \neg G(x))]$ as a singular term. No paradox is forthcoming, in other words; rather, what follows is only that the Russellian concept in question has no object corresponding to it as a concept-correlate.

The problem now, however, is how do we know that any nominalized predicates denote at all. Indeed, in the logical framework as described so far, even the Abelardian thesis mentioned earlier that no nominalized predicate at all denotes can be consistently maintained. That thesis, however, as already noted, is not consonant with our use of nominalized predicates in natural language and leads us away from and not towards the development of conceptual realism. What is needed instead is a principled way of positing the existence of intensional objects as the correlates of most, even if not of all, of our concepts.

The obvious solution is to turn once again to Frege's double correlation thesis. For just as that thesis provides a way of consistently positing properties and relations in the system $\square \lambda$ HST $^{*}$, so too it can be used to posit the same properties and relations in the new system that is free of existential presuppositions regarding singular terms. That is, on the basis of Frege's double correlation thesis we can assume that at least all of the concepts that have correlates in $\square \lambda$ HST $^{*}$ also have correlates in the new system. This assumption is formally described in [2], [3] and [4] in terms of a certain axiom scheme $\left(\exists / \mathrm{HSCP}_{\lambda}^{*}\right)$, and

\footnotetext{
${ }^{1}$ See [1] for a general discussion of logic free of existential presuppositions for singular terms.
} 
the result of adding this scheme to the new system in question results in the intensional logic I have called HST ${ }_{\lambda \square}^{*}$ (because of its close similarity to $\square \lambda \mathrm{HST}^{*}$ ). (As noted in [4], $\lambda \mathrm{HST}^{*}$ and $\mathrm{HST}_{\lambda}^{*}$ are equiconsistent, and, as a result, it is easily seen that $\square \lambda \mathrm{HST}^{*}$ and $\mathrm{HST}_{\lambda \square}^{*}$ are too.) It is the system HST $\mathrm{H}_{\square}^{*}$ that we propose taking as the basis for our development of conceptual realism. ${ }^{2}$

\section{What Are the Natural Numbers and Where Do They Come From?}

The question of the ontological status of the natural numbers and of our epistemological grasp of them provides a useful introduction to the kind of analysis we intend here between referential concepts and the intensional objects that are their correlates. For there are three ontological aspects in which the natural numbers have in general been described by philosophers, and each of them, it turns out, corresponds to one or another of the three types of expressions involved in our conceptual realist version of Frege's double-correlation thesis.

The first type of expression is that of numerical quantifier phrases. The entities associated with these expressions are usually called 'quantities' - e.g., five chairs, two cats, ten people, one president, etc. Their basic use, according to conceptualism, is as referential expressions, and what they stand for as such are referential concepts. The quantities that are usually associated with these expressions, according to the conceptual realism we want to defend here, are really the intensional objects that are the correlates of the referential concepts they stand for in their basic use. That is to say that quantities, on our proposal, are the intensions of certain referential concepts; namely, those expressed by numerical quantifier phrases.

Now some numerical quantifier phrases do not refer to any particular kind of object, but to objects in general; and for that reason we shall call them pure numerical quantifier phrases. The ones that we are interested in here can be contextually defined as follows:

$$
\begin{aligned}
(0 x) \varphi x= & d f \neg(\exists x) \varphi x, \\
(1 x) \varphi x= & d f(\exists x)(\varphi x \wedge(0 y)[y \neq x \wedge \varphi(y / x)]), \\
(2 x) \varphi x= & d f(\exists x)(\varphi x \wedge(1 y)[y \neq x \wedge \varphi(y / x)]), \\
& \text { etc. }
\end{aligned}
$$

Under the ontological aspect of quantities, the natural numbers, according to conceptual realism, are none other than the pure quantities that are the conceptcorrelates of the referential concepts expressed by pure numerical quantifier phrases.

\footnotetext{
${ }^{2}$ Another option is available here as well, it should be noted; namely, the system $\mathrm{T}^{*}$ described in [2], chapter V. This system is motivated by a different way of extending the ramified logic for constructive conceptualism described in [6] into a logic for holistic conceptual realism.
} 
The second type of expression is that of the cardinal number predicatese.g., 'has twelve instances', or even 'has twelve members'. The entities associated with these predicates are usually called cardinal number properties. Thus, to take one of Frege's examples, the class of Apostles has twelve members, or equivalently, the property of being an Apostle has twelve instances. In Bertrand Russell's 'no-classes' version of logicism, the natural numbers were in effect identified with the finite cardinal number properties. Of course, in conceptualism predicates stand for concepts and not for properties; but then in conceptual realism the properties in question are just the intensional objects denoted by the nominalized forms of those predicates as abstract singular terms. The predicates themselves can be defined in terms of the corresponding quantifier phrases as follows. (We retain the parentheses here so as to emphasize that we are defining predicates in these cases and not abstract singular terms.)

$$
\begin{aligned}
0()= & { }_{d f}[\lambda F(0 x) F(x)](), \\
1()= & d_{d f}[\lambda F(1 x) F(x)](), \\
2()= & { }_{d f}[\lambda F(2 x) F(x)](), \\
& \text { etc. }
\end{aligned}
$$

(A $\lambda$-abstract of the form $[\lambda F \varphi]$ is an abbreviation for a $\lambda$-abstract of the form $[\lambda x(\exists F)(x=F \wedge \varphi)])$. Note, incidentally, that these definitions indicate the general way in which a predicable (first-level) concept is to be correlated with a referential (second-level) concept in accordance with Frege's double correlation thesis. Also, in accordance with conceptual realism's version of Frege's thesis, note that the cardinal number properties that are the intensions or conceptcorrelates of the predicable concepts that the above predicates stand for are none other than the pure quantities already identified as the natural numbers. In other words, the natural numbers under either of these ontological aspects come to the same thing, as far as conceptual realism is concerned.

Finally, the third and last type of expression for the natural numbers are the numerals as abstract singular terms. These are the expressions most favored in mathematics since the entities associated with them are the natural numbers in their most simple or direct ontological aspect. But their simplicity of expression is misleading and leads to the epistemological problem of how the natural numbers are conceptually accessible to us. This problem, along with the problem of how intensional objects are in general conceptually accessible to us, is resolved in conceptual realism through its version of Frege's double correlation thesis. For all abstract singular terms, including numerals, according to conceptual realism, are ultimately explained on the basis of a nominalizing transformation of predicates. Thus, the numerals in particular can be defined as follows:

$$
\begin{aligned}
0= & d_{f}[\lambda F(0 x) F(x)], \\
1= & d_{f}[\lambda F(1 x) F(x)], \\
2= & { }_{d f}[\lambda F(2 x) F(x)], \\
& \text { etc. }
\end{aligned}
$$


Note that on this analysis the natural numbers are epistemically accessible to us in just the same way that concept-correlates in general are - namely, through the concepts whose correlates they are. That is, we are conceptually able to think about the natural numbers because we are conceptually able to lay hold upon them as the intensions of the (predicable concepts determined by the) referential concepts that pure numerical quantifier phrases stand for. And this conceptual ability, we have said, is just what in conceptual realism is explained by Frege's double-correlation thesis.

Finally, that the natural numbers denoted by numerals as abstract singular terms turn out to be just the pure quantities that are the intensions of the referential concepts expressed by pure numerical quantifiers is a natural, and not a fortuitous, result. For it explains why children first learn about quantities, e.g. two apples, four cows, ten trees, etc., and only later, after they have formed the concept of an object simpliciter, learn about the numbers themselves. That is, children learn to think about the natural numbers as abstract objects by learning first to objectify the content of the referential concepts expressed by numerical quantifier phrases, and then, by means of the concept of an object simpliciter, they learn to think about the natural numbers as the objectified contents of the referential concepts expressed by pure numerical quantifier phrases. And that this is possible is just what is explained in conceptual realism by Frege's double-correlation thesis.

\section{Referential Concepts and Quantifier Phrases}

Referential concepts can be expressed not only by numerical quantifier phrases, but by quantifier phrases in general. Moreover, just as the referential concepts expressed by pure numerical quantifier phrases are constructed on the basis of those expressed by numerical quantifiers and the concept of an object simpliciter, so too referential concepts that refer to objects in general are constructed in a similar way on the basis of those that refer to objects of a given sort.

Now by a sort, or sortal concept, we here mean a type of concept whose use in thought and communication is associated with certain identity criteria, i.e., criteria by which we are able to distinguish and count objects of the sort in question. Sortal concepts are expressed in natural language not by predicates, it should be noted, but by common nouns, or what we shall call common names.

Not every common name stands for a sort in the sense intended here, however. In particular, the common names 'thing', 'individual', and 'object' (which we assume to be synonymous) do not stand for a sortal concept, because the concept of a thing, individual or object simpliciter is not associated in its use with any particular identity criteria. Rather, according to conceptualism, the concept of a thing, individual or object simpliciter is constructed on the basis of the concept of an object of a sort (cf. [13]). Reference to objects of a given sort is accordingly not a restricted form of reference to objects in general. This is not to say that the two forms of reference do not lead to logically equivalent forms of assertions, the way, for instance, an assertion of 'all men are mortal' 
is logically equivalent to one of 'every object is such that if it is a man, then it is mortal'. Being logically equivalent, however, only means that the two forms of assertion have the same truth conditions, and not that they represent the same cognitive act of assertion as well; for whereas the referential concept used in the one assertion is that expressed by 'all men', the referential concept used in the other is that expressed by 'every object'. This means that if we want our theory of logical form to be perspicuous not only in the way it specifies the truth conditions of our assertions, but also in the way it specifies their cognitive structure as well, then we need to add to our logical grammar a new syntactic category of common names, and redefine first-order quantifier phrases as being of the form $(\forall x S),(\forall y T),(\exists z S),(\exists x T)$, etc., in which $S$ and $T$ are common names. Thus, for example, where $S$ stands for the sort raven and $F$ stands for the predicable concept of being black, a categorical judgment that all ravens are black or that some ravens are not black can be represented by the logical forms $(\forall x S) F(x)$ and $(\exists x S)[\lambda x \neg F(x)](x)$, respectively. (We use $[\lambda x \neg F(x)]$ to stand for the concept of not-being-black, which is being predicated of some ravens. We distinguish in this way negations that are internal from those that are external to a predication.)

Now although the concept of an object simpliciter is constructed on the basis of the concept of an object of some sort or other, this does not mean that the construction is by means of an explicit definition. That is, where $S$ is a sortal common name variable, we do not adopt the following as definitions:

$$
\begin{aligned}
& (\forall x \text { Object }) \varphi x={ }_{d f}(\forall S)(\forall x S) \varphi x, \\
& (\exists x \text { Object }) \varphi x={ }_{d f}(\exists S)(\exists x S) \varphi x .
\end{aligned}
$$

This kind of construction may in fact be all that there is to the concept of an object (thing, or individual) simpliciter, but we want to leave open the possibility that at some stage of conceptual development we are able to refer to objects for which no identity criteria can even in principle be constructed. For this reason, we will not assume that all common names either stand for sortal concepts or are definable, in one way or another, in terms of those that do. However, instead of using ' $\forall x$ Object $)$ ' or ' $(\exists x O b j e c t)$ ' in representing references to all, or some, objects simpliciter, we will continue to use the standard quantifier phrases ' $(\forall x)$ ' and ' $(\exists x)$ ' for this purpose.

Finally, let us also be note that not all common names are simple; that is, some are complex and involve the use of a 'defining' relative clause that further specifies the kind of object that is being referred to. Thus, for example, the sentence 'Every citizen (who is) over twenty-one is eligible to vote' contains the complex common name 'citizen (who is) over twenty-one'. We shall use the notation, ' $(\forall x S / \varphi x)$ ' and ' $(\exists x S / \varphi x)$ ' to represent references based upon such complex common names. For instance, ' $\forall x$ Citizen/x is-over-21)' can be used to represent a reference to all citizens (who are) over twenty-one. 


\section{Singular Reference}

The combination of a quantifier phrase with a predicate expression is one example of the linguistic rule that divides a sentence into a "nominal" (referring) expression and a "verbal" (predicating) expression. More than that, however, it also illustrates in a perspicuous way what we mean by the complementarity of referential and predicable concepts; namely, that it is their combination and mutual saturation in particular acts of thought, including speech acts, that accounts for the referential and predicable aspects of those acts. It is natural, accordingly, that we should seek a similar explanation when the noun phrase is either a definite description or a proper name; that is, when the reference is purportedly singular.

I have in fact already given such an explanation in [7] and [8], which I shall only briefly describe here. The general idea is that when a definite description or proper name is used as a referential noun phrase, i.e., to express the result of applying a referential concept, then its proper representation in logical syntax is not as a singular term but as a quantifier expression. In addition, since the referential use of a definite description or proper name may be with or without existential presupposition, then there really are two sorts of referential concepts that might be involved in such a use, namely, one in which the singular reference is with, and the other without, existential presupposition.

Now a quantifier representation of the distinction between the referential use of a proper name that is with, as opposed to without, existential presupposition is already at hand in the distinction between the universal and existential quantifier signs. Thus, for example, an assertion that Pegasus can fly in which the purported reference to Pegasus is with existential presupposition can be perspicuously represented by

$$
(\exists x \text { Pegasus })[\lambda x \diamond F l y(x)](x),
$$

whereas an assertion of the same form but in which the reference is without existential presupposition can be represented by

$$
(\forall x \text { Pegasus })[\lambda x \diamond F l y(x)](x) .
$$

There is an obvious similarity here in the logical roles we are assigning to proper names and common names, and in fact, as I have proposed in [7] and [8], proper names can be assimilated with sortal common names. For just as the referential concept underlying the use of a sortal common name is associated with certain identity criteria, so, too, the referential concept underlying the use of a proper name brings with it certain identity criteria; namely, those provided (in a given context) by the most specific sortal concept associated with that name's introduction into discourse (as determined by the context of use in question). Of course, proper names are different from common names in that they are used (in a given context) to refer to at most one object, which is why we say that the referential concept underlying their use has singular reference. Proper names can, on occasion, be used to refer to more than one 
object; but unlike the unambiguous use of a common name to refer to a number of objects, a proper name can be used in this way only ambiguously. ${ }^{3}$

Unlike the situation with proper names, a quantifier representation of the distinction between the referential use of a definite description that is with, as opposed to without, existential presupposition requires the introduction of two new quantifier signs, such as, e.g. $\exists_{1}$, and $\forall_{1}$. Thus, where $S$ is a common name and $F$ and $G$ are monadic predicates, an assertion of the form,

The $S$ that is $F$ is $G$,

in which the definite description is being used with existential presupposition will be represented by

$$
\left(\exists_{1} x S / F(x)\right) G(x)
$$

and an assertion of the same form but in which the definite description is being used without existential presupposition will be represented by

$$
\left(\forall_{1} x S / F(x)\right) G(x) .
$$

In both cases, it should be noted, the definite description is not being represented in our logical syntax as a "singular term" (i.e., as an expression that can be meaningfully substituted for an individual variable). In this regard our analysis is similar to Russell's, even though the results are quite different.

Now the difference between our analysis and Russell's is noteworthy here because of the light it sheds on the two ways in which logical forms can be perspicuous. For a slight reformulation of Russell's contextual analysis shows that the two analyses are formally equivalent and therefore describe the same truth conditions. That is, the biconditionals,

$$
\left(\exists_{1} x S / F(x)\right) G(x) \leftrightarrow(\exists x S)[(\forall y S)(F(y) \leftrightarrow y=x) \wedge G(x)],
$$

and

$$
\left(\forall_{1} x S / F(x)\right) G(x) \leftrightarrow(\forall x S)[(\forall y S)(F(y) \leftrightarrow y=x) \rightarrow G(x)],
$$

in which the right-hand sides represent Russell's contextual analysis, ${ }^{4}$ are to be taken as valid in our intensional logic for conceptual realism. Regardless of this formal equivalence, however, it would be inappropriate in conceptualism to represent the structure of an assertion of the form in question-i.e., its structure as a speech act - by either of the wffs that correspond to Russell's analysis. This is because the logical forms determined by Russell's analysis specify only the truth conditions for an assertion of the form 'The $\mathrm{S}$ that is $\mathrm{F}$ is $\mathrm{G}$ ', and not also its cognitive structure. In particular, although Russell's analysis provides a perspicuous representation of the truth conditions for such an assertion, it

\footnotetext{
${ }^{3}$ Proper names can also be used to construct identically appearing common names, as, for example, when we say of someone wise that he is a Solomon, or of someone who has betrayed his friend that he is a Judas.

${ }^{4}$ Russell did not himself distinguish between the use of a definite description with, as opposed to without, existential presupposition. We correct for that omission in our reformulation of his contextual analysis.
} 
does not also provide a perspicuous representation of the referential and predicable concepts that make up the cognitive structure of that assertion. Thus, regardless of whether the referential concept that is being applied in such an assertion is with or without existential presupposition, it is in either case the same predicable concept that is being applied. In the wffs corresponding to Russell's analysis, however, it is not the same but a different predicable concept that is being applied in each case, as can be seen by using $\lambda$-abstracts to stand for the predicable concepts in question. That is, on Russell's analysis, the assertion is described as having one of the following forms,

$$
(\exists x S)[\lambda x((\forall y S)(F(y) \leftrightarrow y=x) \wedge G(x))](x),
$$

and

$$
(\forall x S)[\lambda x((\forall y S)(F(y) \leftrightarrow y=x) \rightarrow G(x))](x),
$$

in which it is clear that the predicable concept that informs the assertion with a predicable nature is different in each case. Note also that whereas the assertion in question is the result of jointly applying a complex referential concept with a simple predicable concept, what is represented by the wffs corresponding to Russell's analysis is, at best, an assertion that is the result of jointly applying a simple referential concept with a complex predicable concept.

Finally, if taken literally, there appear to be two referential concepts (as represented by quantifier phrases) involved in the one assertion in either case of Russell's analysis, whereas of course there is really just one referential concept that is being applied in any assertion of the form in question. ${ }^{5}$ This means that in a proper analysis of the structure of an assertion as an overtly expressed act of thought, no quantifier expression should occur as such, i.e., as standing for a referential concept, other than the initial quantifier expression that stands for the one referential concept that is being applied in that act. Our general thesis will be that an applied predicable concept is never constructed on the basis of a referential concept, applied or otherwise, but only on the basis of the intensional content of such a referential concept, i.e., only on the basis of the concept-correlate of that referential concept.

\section{The Intensions of Referential Concepts as Com- ponents of Applied Predicable Concepts}

As already indicated, we take the intension of a referential concept to be the concept-correlate of the predicable concept determined by that referential concept. In general, accordingly, where $S$ is a proper or common name (complex or simple, and including the ultimate superordinate common name 'Object' or 'Individual'), and $Q$ is a quantifier symbol (representing a determiner of natural language), we may define the predicate expression, and thereby the abstract

\footnotetext{
${ }^{5}$ In the above formulations the second quantifier phrase in each occurs with the complex predicate, i.e., within the $\lambda$-abstract.
} 
singular term that is its nominalized form, that is determined by the quantifier phrase $(Q x S)$ as follows:

$$
[Q x S]={ }_{d f}[\lambda F(Q x S) F(x)] .
$$

Thus the 'quantities' that we mentioned earlier, namely five chairs, two cats, ten people and one president, are just the intensional objects [5xChair], [2xCat], $[10 x$ Person $]$ and $[1 x$ President $]$ corresponding to the numerical quantifier phrases '(5xChair $)$ ', '(2xCat)', '(10xPerson $)$ ', and '(1xPresident)'. (Pluralizing a common name is a morphosyntactic feature of surface grammar that has no counterpart in our present intensional logic.) The quantities corresponding to pure numerical quantifiers are of course just the natural numbers. Thus, for instance, by our convention for deleting the common name 'Object', $[3 x$ Object $]=$ $[3 x]$, which by our earlier definition is just the number 3 itself.

Now aside from the natural numbers and the 'impure' quantities, the intensional objects of referential concepts in general have a fundamental role to play in the conceptualist theory of predication we have briefly outlined in section one. In particular, as indicated at the end of the last section, we shall assume that in any context in which a predicable concept is applied so as to inform a mental or speech act with a predicable nature, it is only a fully intensional predicable concept, i.e., a concept whose construction is based on the intensions of referential concepts instead of on those referential concepts themselves, that is actually applied. Formally, this means that an applied predicable concept is represented only by a predicate expression in which no referential (quantifier) expression occurs other than as part of an abstract singular term (such as a nominalized wff, in which case the referential role of that expression has been deactivated and replaced in effect by its intensional content).

Consider, for example, a context in which the following argument is asserted.

John finds a unicorn;

therefore, there is a unicorn such that John finds it.

In this context, 'John' is being used as a referential expression in the premise, but not in the conclusion; and, similarly, whereas 'a unicorn' is being used referentially in the conclusion, it is not being used referentially in the premise. Assuming that 'John' is being used in this context with existential presupposition, these differences can be represented as follows (where it is not the referential concept of the premise or conclusion, respectively, that is a component of the predicable concept of the conclusion or premise but its intensional content):

$$
\begin{aligned}
& (\exists x J o h n)[\lambda x \text { Finds }(x,[\exists y U n i c o r n])](x) ; \\
& \text { therefore, }(\exists y \text { Unicorn })[\lambda y \text { Finds }([\exists x J o h n], y)](y) .
\end{aligned}
$$

An activated referential concept is never part of what informs a mental or speech act with a predicable nature, in other words, but only functions as what informs that act with a referential nature. This means that an applied predicable concept is never formed on the basis of a referential concept, but only 
on the basis of the intensional content of such a referential concept, i.e., only on the basis of the concept-correlate of that referential concept. Of course, corresponding to every predicate expression, there will always be a fully intensionalized predicate expression that is its intensionalized counterpart; namely, the predicate expression that is formed in the exact same way, except for having a nominalized quantifier phrase as a component in its analysis wherever that quantifier phrase occurs in the original predicate expression. Indeed, it is for this reason that we can say that every predicable concept can in principle be applied in this theory; for to apply a predicable concept in this theory means in part to intensionalize it, i.e., transform its expression into its fully intensional counterpart, and then to apply that result. In other words, just as reference is fundamentally an intentional act in which we purport to refer to an object or objects of a certain kind, regardless of whether there really are objects of that kind or not, so predication, in our account, is an intensional act in which only a fully intensionalized predicable concept is applied. As we observe below, this explains why, in particular, we can say that John seeks a unicorn, without it following that there is a unicorn that John is seeking. It will also explain how different people can have cognitive attitudes toward the same purported object, even though no such object actually exists.

Before turning to these accounts, however, let us note that not only must a predicate expression that represents the predicable concept of an assertion be fully intensionalized, but so must the quantifier phrase that represents the referential concept of that act, which means that the "defining" relative clause, if any, of that quantifier phrase must also be similarly intensionalized. That is, no referential (quantifier) expression is to occur in any wff representing the defining relative clause of a referential expression that stands for an applied referential concept, unless that expression occurs as part of an abstract singular term (where its referential role has been deactivated and replaced by its intensional content). Thus, for example, in an assertion of the form,

Every man who owns a donkey feeds it,

we have a complex referential concept being applied that is expressed by the quantifier phrase, 'Every man who owns a donkey'; and in this referential expression the defining relative clause, 'who owns a donkey', contains the simple quantifier phrase, 'a donkey'. No reference is being made in this assertion to a donkey, but only to every man who owns a donkey; that is, the referential role of the quantifier phrase 'a donkey' has been deactivated in this assertion and replaced by its intensional content. Accordingly, assuming that the pronoun 'it' is being used as an anaphoric substitute for the quantifier phrase 'any donkey that he owns', the proper logical representation of this assertion can be given 
as follows: ${ }^{6}$

$(\forall x M a n / O w n s(x,[\exists y$ Donkey $]))(\lambda x F e e d s(x,[\forall y$ Donkey/Owns $(x, y)])](x)$.

\section{Intensional Versus Extensional Predicable Con- cepts}

One of the puzzles that our theory of the intensionalization of applied predicable concepts is designed to explain is how one argument of the same logical form as another can be valid, while the other is invalid. The following two arguments, for example,

John finds a unicorn;

therefore, there is a unicorn such that John finds it.

John seeks a unicorn;

therefore, there is a unicorn such that John seeks it.

clearly have the same logical form; and yet whereas the first is intuitively valid, the second is just as intuitively invalid. But, of course, arguments of the same logical form must either both be valid or both be invalid.

The usual way taken to resolve this sort of puzzle is to resort to paraphrasee.g., to maintain that 'seeks' should to be paraphrased as 'tries to find'-and then to claim on the basis of such a paraphrase that the arguments are not really of the same logical form after all. ${ }^{7}$ Our explanation is more simple and turns on the obvious fact that whereas 'finds' stands for a relational predicable concept that is extensional for objects in its range as well as for objects in its

\footnotetext{
${ }^{6}$ Note that although the following simpler wff,
}

$$
(\forall x M a n)(\forall y \text { Donkey })(\text { Owns }(x, y) \rightarrow \text { Feeds }(x, y)),
$$

has the same truth conditions as the wff in our analysis (because of the extensionality of 'Feeds'), it cannot, for reasons already explained, be taken as a perspicuous representation of the structure of the assertion as a speech act. Nor for that matter can

$$
(\forall x M a n)[\lambda x F e e d s(x,[\forall y \text { Donkey/Owns }(x, y)])](x),
$$

which at least represents the act in terms of only one referential concept, albeit the wrong one. It is not the simple referential concept expressed by 'every man' that is being applied in this assertion, but the complex referential concept expressed by 'every man who owns a donkey'.

${ }^{7}$ Compare Richard Montague's 'On the Nature of Certain Philosophical Entities', in [12]. Montague renounced this approach in his later papers, 'Universal Grammar' and 'The Proper Treatment of Quantification in Ordinary English', also reprinted in [12]. In fact, the theory we describe here, while it differs from Montague's later theory in a number of ways, nevertheless has much in common with his later theory. Indeed, our whole program of conceptual realism may be seen as a new way to approach Montague Grammar, including in particular replacing Montague's logical realist intensional logic with its sense-denotation distinction by a conceptual realist version of second-order predicate logic with nominalized predicates as abstract singular terms. 
domain, 'seeks' stands for a relational predicable concept that is extensional only for the objects in its domain. Formally, the fact that 'finds' stands for a relational predicable concept that is extensional in its range can be expressed by the following meaning postulate schema (where $Q$ is a schematic quantifier sign representing the determiners of natural language):

$$
[\lambda x \operatorname{Find} s(x,[Q y S])]=[\lambda x(Q y S) \text { Finds }(x, y)] .
$$

In particular, as an instance of this schema we have,

$$
[\lambda x \operatorname{Finds}(x,[\exists y U n i c o r n])]=[\lambda x(\exists y U \text { nicorn }) \operatorname{Finds}(x, y)],
$$

which, together with $\lambda$-conversion and the meaning postulate expressing the fact that the same relational concept is extensional in its domain as well, shows that the first of the above two arguments is indeed valid after all. Such a justification cannot also be given for the second argument, on the other hand, since the relational concept that 'seeks' stands for is not extensional for the objects in its range. Thus the important point about where the two arguments differ is not in their form, but in the kind of relational concept each is based upon, i.e., whether or not the relational concept in question is extensional for the objects in its range as well as for the objects in its domain. ${ }^{8}$

It should be noted that an instance of the above meaning postulate schema identifies only the concept-correlates of the predicable concepts that the $\lambda$ abstracts stand for (in their role as predicates), and not also those predicable concepts themselves. Of course, strictly speaking it is meaningless to speak of identity as a relation between concepts as unsaturated cognitive capacities, because identity is a relation only between objects. But even granting some indirect sense in which concepts might be said to be identical (such as might be given by the principle of intensionality, ( $\square$ Ext*), described in section 3), it would still be inappropriate to speak of the concepts in the above instance of the given meaning postulate as being identical; for the concepts 'differ' in that where one has a referential concept as a component of its analysis, the other

\footnotetext{
${ }^{8}$ Strictly speaking, meaning postulates are analytic truths, and therefore, like logical truths, they are not merely suppressed premises of an argument, but function as part of the analytic background within which all argumentation is given.

We should perhaps note in this context that the so-called de re interpretation of 'John seeks a unicorn' has nothing to do with the relational concept that 'seeks' stands for, but rather is based instead on the use of ellipsis. That is, the sentence in question in that case is really 'John seeks a certain unicorn', which, by ellipsis, can be transformed into 'John seeks a unicorn'. The argument, 'John seeks a certain unicorn; therefore there is a unicorn such that John seeks it', is indeed valid; but this is because of the following meaning postulate for the quantifier phrase 'a certain $S$ ' (symbolized here by ' $\left(\exists^{c} y S\right)$ '):
}

$$
\left[\lambda x \operatorname{Seeks}\left(x,\left[\exists^{c} y S\right]\right)\right]=[\lambda x(\exists y S) \operatorname{Seeks}(x, y)] .
$$

This postulate is analytically true not because of the relational concept that 'seeks' stands for, but rather because it is an instance of the following meaning postulate schema:

$$
\left[\lambda x_{1} \ldots x_{n} R\left(x_{1}, \ldots, x_{n},\left[\exists^{c} y S\right]\right)\right]=\left[\lambda x_{1} \ldots x_{n}(\exists y S) R\left(x_{1}, . ., x_{n}, y\right)\right] .
$$


has the concept-correlate of that referential concept instead. Again, the point of the identity is not that the predicable concepts are the same, but rather that they have the same intensional content, i.e., the same concept-correlate.

Note that even if the concepts themselves are not the same, the fact that they have the same intension (concept-correlate) means that they have the same extension, i.e., whatever falls under the one concept falls under the other. Falling under the one concept, however, means standing in a certain conceptual relation to an intensional object, whereas falling under the other means standing in the same relation to a concrete object. Nothing follows, of course, to the effect that an intensional object is a concrete object; but still, because this situation is typical of most, if not all, relational concepts, we should be cautious in not drawing that conclusion in other cases as well. One type of context in which this caution is particularly important, for example, is where an identification is made by means of the relational concept that the copula 'is' stands for, as when 'is' is used with a common name, a proper name, or a definite description. An assertion of the form 'John is a teacher', for example, will have the following logical form,

$$
(\exists x \operatorname{John})[\lambda x \operatorname{Is}(x,[\exists y \text { Teacher }])](x),
$$

as a perspicuous representation of its cognitive structure. This is because the predicate expression that is applied in this assertion must, on our theory, be intensionalized, which means that, compositionally, the predicable concept expressed is analyzed (or formed) in terms of the intensional content (conceptcorrelate) of the referential concept that the quantifier phrase 'a teacher' stands for, and not in terms of that referential concept itself. But note that nothing follows here to the effect that John, a concrete object, is identical with the intensional object in question. This is because the relational concept that the copula 'is' stands for is not quite the same thing as the relation of identity. The connection between the two is given by the following meaning postulate (schema):

$$
[\lambda x I s(x,[Q y S])]=[\lambda x(Q y S)(x=y)] .
$$

Thus, from the assertion that John is a teacher it does follow (by Leibniz's law and $\lambda$-conversion) that John and some teacher are identical, which can be represented as follows:

$$
(\exists x J o h n)(\exists y \text { Teacher })(x=y) .
$$

Note that although this last wff correctly describes the truth conditions for an assertion of the form that John and some teacher are identical, it cannot also, in our theory, represent the structure of that assertion as a speech act. For in our theory such an assertion must be the result of applying one referential concept together with one predicable concept, and what would be needed for that purpose in this case is a way of representing the conjunctive referential concept that the quantifier phrase 'John and some teacher' stands for. Thus, for example, where ' $(\exists x S \wedge \exists y T)$ ' is a quantifier expression binding two variables, each associated with a different proper or common name, the cognitive 
structure of an assertion of the form 'John and some teacher are identical' can be perspicuously represented as follows:

$$
(\exists x J o h n \wedge \exists y \text { Teacher })[\lambda x y(x=y)](x, y) .
$$

The same observations apply to uses of 'is' as a copula in identification with respect to a proper name or definite description. Thus, for example, a perspicuous representation of the cognitive structure of an assertion of the form 'John is the thief' can be given as follows,

$$
(\exists x J o h n)\left[\lambda x \text { Is }\left(x,\left[\exists_{1} y \text { Thief }\right]\right)\right](x),
$$

which, even though it has the same truth conditions, is to be distinguished from a perspicuous representation of an assertion of the form 'John and the thief are identical'. Similarly, a perspicuous representation of an assertion of 'the morning star is the evening star' can be given as follows,

$$
\left(\exists_{1} x \text { MorningStar }\right)\left[\lambda x \text { Is }\left(x,\left[\exists_{1} \text { yEveningStar }\right]\right)\right](x)
$$

which is to be distinguished from a perspicuous representation of 'the morning star and the evening star are identical', even though assertions of either sentence will have the same truth conditions. ${ }^{9}$

\section{The Intentional Identity of Intensional Ob- jects}

The use of the copula in classification, as in ' $\mathrm{x}$ is a teacher', has a predicable counterpart that, aside from its difference in conceptual or logical role, comes close to being synonymous with the common name used in that classification. Corresponding to the common name 'teacher', for example, we also have the predicate $[\lambda x \operatorname{Is}(x,[\exists y$ Teacher $])]$, which when nominalized, can be read as 'to be a teacher'. In general, in other words, every common name $S$ has a predicable counterpart $[\lambda x I s(x,[\exists y S])]$, which in turn can be nominalized and read as 'to be an $S$ ', or, equivalently, as 'being an $S$ ', which, appositionally, can also be read as 'the property of being an $S$ '.

Closely related to the predicable counterpart of a common name $S$ there is another predicate that, when nominalized, is also read as 'to be an $S$ ', namely

\footnotetext{
${ }^{9}$ Note that a conjunctive quantifier phrase such as 'the morning star and the evening star' can be broken up (e.g., by a rule of transformational grammar) so that from 'the morning star and the evening star are identical' we can derive 'the morning star is identical with the evening star'. The point is that if in asserting the latter sentence we mean to refer to both the morning star and the evening star, and assert that they are identical, then in doing so we are really applying a single conjunctive referential concept rather than two non-conjunctive referential concepts. (If we mean to refer only to the morning star, however, then, properly speaking, we should use the copula alone, instead of the phrase 'is identical with'.) Every basic assertion, in other words, consists of the application of but one referential concept and one predicable concept, and where the latter is a relation, this only means that the referential concept is conjunctive, and not that there are multiple referential concepts being applied together.
} 
$[\lambda x(x=[\exists y S])]$. Despite their common reading in natural language, however, these predicates are in no sense equivalent, and, for our purposes, we shall distinguish them here by reading the latter instead as 'to be an intensional $S$ '. Thus, in addition to a classificatory common name concept $S$ and its predicable counterpart of being an $S$, we also have the predicable concept of being an intensional $S$. This latter notion, like that of being an $S$, also turns out to be the predicable counterpart of a common name concept, except that in this case the common name concept is constructed on the basis of the predicable concept, rather than the predicable concept being constructed on the basis of the common name concept. In addition, despite the difference in content between the new common-name concept and the original, the two are expressed in natural language by the same common name. That is, the same common name is used in natural language sometimes to express the one concept and sometimes the other, just as the same predicate expression is used in natural language to stand for either of their predicable counterparts. For our purposes, we shall distinguish the two by distinguishing between the original common name $S$ and a derived common name $S^{*}$ that is contextually defined as follows (where $Q$ is a schematic quantifier sign):

$$
\left(Q x S^{*}\right) \varphi=_{d f}(Q x / x=[\exists y S]) \varphi .
$$

An important claim that we shall make here is that it is the ambiguity in natural language between being an $S$ and being an intensional $S$, i.e., between being an $S$ and being an $S^{*}$, which is the source of our various puzzles about intentional identity. This means that in resolving these puzzles we must distinguish not only between a de re and a de dicto attitude toward an $S$, in which the latter really amounts to a de dicto attitude toward an $S^{*}$, but also, and more importantly, between a de re attitude toward an $S$ and a de re attitude toward an $S^{*}$. Our puzzles about intentional identity arise, it turns out, because we use the same expression in natural language to describe the one kind of de re attitude as to describe the other.

The best known of the puzzles about intentional identity has been given by Peter. Geach, who observes that "we have intentional identity when a number of people, or one person on different occasions, have attitudes with a common focus, whether or not there actually is something at that focus' ([11], p. 147). For example, a reporter in Gotham village, describing what he takes to be an outbreak of witch mania and not of actual witchery, asserts the following:

Hob thinks a witch has blighted Bob's mare, and

Nob wonders whether she (the same witch) killed Cob's sow.

The problem here, as Geach observes, is to explain how 'a pronoun in one indirect-speech clause is on the face of it bound to a quantifier phrase in another such context' (ibid., p. 150); that is, to explain how the pronoun 'she' (with its parenthetical phrase 'the same witch') that occurs in the second part of the reporter's assertion is bound by the quantifier phrase 'a witch' that occurs in the first part of his assertion. We shall refer to this problem in its general form as the problem of intentional identity. 
Now the simplest explanation of how the pronoun 'she' is bound to the quantitier phrase 'a witch' is that the reporter intends to refer in the second part of his assertion to a witch, and in particular to the same witch that he refers to in the first part of his assertion; and therefore that he is really describing the de re attitudes that Hob and Nob have toward the same witch. Formally, this interpretation can be described as follows, where ' $x$ has blighted Bob's mare' is symbolized by $F(x)$, and ' $x$ killed Cob's sow' is symbolized by $G(x)$.

$$
(\exists x W i t c h)[\lambda x(\text { Thinks }([\exists y H o b],[F(x)]) \wedge \text { Wonders-Whether }([\exists z N o b],[G(x)]))](x) \text {. }
$$

Note that in this logical form there is but one referential expression occurring as such, namely ' $(\exists x W i t c h)$ ', and, similarly, one predicate expression occurring as such, namely the $\lambda$-abstract that is specified in terms of a conjunction. We assume that the reporter's use of 'Hob' and 'Nob' is with, and not without, existential presupposition, which means that their proper symbolic counterparts are of the form ' $(\exists y H o b)$ ' and ' $(\exists z N o b)$ ', respectively. But because in this version of the de re interpretation 'Hob' and 'Nob' are not being used referentially but as part of a fully intensionalized predicate, then ' $(\exists y H o b)$ ' and ' $(\exists z N o b)$ ' must be replaced by their intensional correlates, i.e., by their nominalized forms ' $[\exists z H o b]$ ' and ' $[\exists z N o b]$ ', respectively.' Finally, in regard to the abstract singular terms $[F(x)]$ and $[G(x)]$, it should be kept in mind that by our earlier notational conventions, these expressions are really nominalizations of the wffs $F(x)$ and $G(x)$, respectively.

One of the problems with the above analysis is that it construes the reporter's conjunction of two assertions as a basic assertion with a conjunctive predicate. That is, instead of exercising one referential concept with one predicable concept, the reporter is really exercising two referential concepts, each with a different predicable concept. In addition, the one referential concept that the above analysis describes the reporter as applying commits him to the existence of a real witch, when in fact he means to commit himself only to an intensional witch that is the 'common focus' of Hob's and Nob's cognitive attitudes. (This fact is not determined by the surface form of his assertion, but by the context in which it is made, namely that he is reporting only on what he takes to be witch mania and not on actual witchery.)

Now both of these problems are resolved, even if not entirely satisfactorily, in what is called the de dicto interpretation of the reporter's compound assertion. On this interpretation, the pronoun 'she' that occurs in the second part of his assertion is really a pronoun of laziness, that is, it occurs there as an anaphoric substitute for some other expression. The expression Geach himself considers is the definite description, 'the witch who blighted Bob's mare'. On this suggestion, the common focus of Hob's and Nob's cognitive attitudes, as described in our version of conceptual realism, is the intensional object that is the correlate of the referential concept that the description 'the witch who blighted Bob's mare' otherwise stands for. That is, on this interpretation the description, and therefore also the pronoun 'she' that is its anaphoric substitute, is not being used referentially in this context, but is meant only to specify the intensional 
object that is part of the de dicto content of Nob's cognitive attitude. In this way we explain how the reporter is committed not to a real witch, but only to an intensional witch.

The other merit of the de dicto interpretation, we have said, is that it correctly interprets the reporter as making two assertions that he conjoins, and hence that he is really using two referential concepts and not just one. In particular, the reporter is now interpreted as using the proper names 'Hob' and 'Nob' referentially, and apparently with, as opposed to without, existential presupposition. The formal version of this interpretation can be given as follows:

$$
\begin{aligned}
& (\exists y H o b)[\lambda y \operatorname{Thinks}(y,[(\exists x W i t c h) F(x)])](y) \wedge \\
& (\exists z N o b)\left[\lambda z W \text { onders-Whether }\left(z,\left[\left(\exists_{1} x W i t c h / F(x)\right) G(x)\right]\right)\right](z) .
\end{aligned}
$$

Note that in this analysis, in which the predicates are fully intensionalized, the quantifier phrases ' $(\exists x W i t c h)$ ' and ' $\left(\exists_{1} x\right.$ Witch $\left./ F(x)\right)$ ' occur as part of nominalized wffs, and therefore do not stand for referential concepts but for their intensional correlates instead. (It should also be kept in mind that the quantifier phrase ' $\left(\exists_{1} x\right.$ Witch $\left./ F(x)\right)$ ' is read in English as the definite description 'the witch who blighted Bob's mare'.)

The major defect with this way of identifying the intensional object that is the common focus of Hob's and Nob's cognitive attitudes as described by the reporter is that it specifies too much. Nob, for example, as far as the reporter is concerned, may not have thought or said anything about Bob's mare, in which case it is incorrect to interpret the reporter as asserting of Nob that he wonders whether the witch who blighted Bob's mare killed Cob's sow. In other words, by interpreting the pronoun 'she' in this context as an anaphoric substitute for some other expression, we may impute more content to the second part of the reporter's assertion than he may in fact intend.

There is another way of identifying the intensional object that is the common focus of Hob's and Nob's cognitive attitudes, however; and, as indicated earlier, it is based not on the de re-de dicto distinction between an attitude toward a real witch and an attitude toward an intensional witch, but on the different distinction between a de re attitude toward a real witch and a de re attitude toward an intensional witch. The reason why our puzzle about intentional identity arises, we have said, is because we use the same common name in natural language to refer to a real witch as to refer to an intensional witch.

Consider, for example, the following somewhat redundant and clearly less stylistic reformulation of the reporter's assertion.

Hob thinks a witch has blighted Bob's mare, and she, the same witch that Hob thinks blighted Bob's mare, is such that Nob wonders whether she killed Cob's sow.

Reformulated in this way, it is again clear that the reporter is making two assertions which he has conjoined, and that in the first part of his conjunctive assertion he is referring only to Hob and that he is describing him as having 
a certain de dicto attitude toward an intensional witch. Prima facie, if we ignore the contextual fact that the reporter is reporting only on what he takes to be witch mania and not on actual witchery, we would also understand him in the second part of his assertion as referring purportedly to the witch that Hob thinks blighted Bob's mare; that is, prima facie we would understand the reporter as giving a de re description of Nob's cognitive attitude regarding a certain witch. ${ }^{10}$ Formally, this interpretation can be described as follows:

$$
\begin{aligned}
& (\exists y H o b)[\lambda y \operatorname{Thinks}(y,[(\exists x W i t c h) F(x)])](y) \wedge \\
& \left(\exists_{1} x W i t c h / T h i n k s([\exists y H o b],[F(x)])[\lambda x W \text { onders-Whether }([\exists z N o b],[G(x)])](x) .\right.
\end{aligned}
$$

What is natural about this interpretation of the reporter's assertion is that it makes clear to whom or what he is purportedly referring by his use of the pronoun 'she' in the second part of his assertion, that is, in his de re description of Nob's cognitive attitude. For if we were to ask that question of him, the natural response would be: the witch that Hob thinks blighted Bob's mare. What is problematic about our interpretation of this answer as represented in the above analysis, however, is that it commits the reporter to the existence of a real witch, when the contextual fact that we chose to ignore is that he intends to refer only to an intensional witch, that is, to a witch* ${ }^{*}$ But this problem is easily corrected; for if we are given the contextual fact that the reporter is reporting only on what he takes to be witch mania and not on actual witchery, then the referential concept that the quantifier phrase 'the witch that Hob thinks blighted Bob's mare' stands for in this context is based not on (the concept of) being a witch but on being a witch*, that is, on being an intensional witch. It is because the same common name is ambiguous in English between being a witch and being a witch*, in other words, that we must sometimes rely on contextual information to determine which of two alternative referential concepts is actually being applied in a given context. This means in particular that the above analysis of the reporter's assertion is essentially correct, except for its use of 'Witch' instead of 'Witch''. That is, the correct interpretation of the reporter's assertion, both in its original form and as reformulated above, once we are given the contextual fact that he does not mean to refer to a real witch, can be given as follows:

$$
\begin{aligned}
& (\exists y H o b)[\lambda y \operatorname{Thinks}(y,[(\exists x W i t c h) F(x)])](y) \wedge \\
& \left(\exists_{1} x W i t c h{ }^{*} / T h i n k s([\exists y H o b],[F(x)])\right)[\lambda x W \text { onders-Whether }([\exists z N o b],[G(x)])](x) .
\end{aligned}
$$

The solution we propose here to Geach's puzzle, needless to say, can easily be generalized and applied to a variety of related puzzles about intentional

\footnotetext{
${ }^{10}$ It may be objected, we agree, that in his original assertion the reporter means to refer not just to the witch that, Hob thinks, blighted Bob's mare, but to Nob as well. In that case, a more appropriate reformulation of the reporter's assertion would utilize the conjunctive quantifier phrase 'Nob and the witch that Hob thinks blighted Bob's mare', and the predicate in question would then be relational and not monadic. For convenience, we ignore the details of this interpretation here, since its formulation and analysis parallels what we have to say for the formulation and analysis that is based on non-conjunctive referential concepts.
} 
identity. The general point is that for each common name concept $S$, whether simple or complex, we need to distinguish a de re interpretation regarding a real $S$ from a de re interpretation regarding an intensional $S$. Which de re interpretation is meant in a given context will in general be determined by the context if it is not already determined by the surface form of the assertion in question. ${ }^{11}$ The notion of an intensional $S$, of course, is based on the notion of an intensional object that is the correlate of a referential concept involving $S$, and, as already explained, our conceptual grasp of such objects is primarily through a conceptualist version of Frege's double correlation thesis and the conceptual counterpart of the process of nominalization. We are conceptually able to lay hold upon and refer to the intensions of our referential concepts, as well as of our predicable concepts, in other words, by starting out from those concepts themselves.

\section{References}

[1] Bencivenga, Ermanno, 'Free Logics', in Handbook of Philosophical Logic, vol. III, D. Gabbay and F. Guenthner, eds., D. Reidel Pub. Co., Dordrecht, 1986, 373-426.

[2] Cocchiarella, Nino B., Logical Investigations of Predication Theory and the Problem of Universals, Bibliopolis Press, Naples, 1986.

[3] Cocchiarella, Nino B., 'Frege, Russell and Logicism: A Logical Reconstruction', in Frege Synthesized, L. Haaparanta and J. Hintikka, eds., D. Reidel Pub. Co., Dordrecht, 1986, 197-252.

[4] Cocchiarella, Nino B., 'Frege's Double Correlation Thesis and Quine's Set Theories NF and ML', Journal of Philosophical Logic 14 (1985), 1-39.

[5] Cocchiarella, Nino B., 'Meinong Reconstructed versus Early Russell Reconstructed', Journal of Philosophical Logic 11 (1982), 183-214.

[6] Cocchiarella, Nino B., 'Conceptualism, Ramified Logic, and Nominalized Predicates', Topoi 5 (1986), 75-87.

[7] Cocchiarella, Nino B., 'Sortals, Natural Kinds and Re-Identification,' Logique et Analyse 80 (1977), 439-74.

\footnotetext{
${ }^{11}$ In some cases the surface grammar of the sentence used to make an assertion makes it clear that the reference that is part of that assertion is only to an intensional, and not to a real, object of the sort in question, E.g., my use of the future tense in an assertion of the form, 'The book I will write next will be about conceptual realism and intensional logic', contextually implies that the purported book in question does not yet exist, and therefore my reference, strictly speaking, is not to a real book, but to a book* ${ }^{*}$, i.e., an intensional book that is an object of my present thoughts about what I will do in the future. Similarly, my use of the past tense in an assertion of the form, 'The first book I wrote is about predication and the problem of universals', contextually implies that the purported book in question does now exist, and therefore my reference is indeed to a real book after all.
} 
[8] Cocchiarella, Nino B., 'Philosophical Perspectives on Quantification in Tense and Modal Logic', in Handbook of Philosophical Logic, vol. II, D. Gabbay and F. Guenthner, eds., D. Reidel Pub. Co., 1983, 309-53.

[9] Frege, Gottlob, Translations from the Philosophical Writings of Gottlob Frege, P. Geach and M. Black, eds., Blackwell, Oxford, 1952.

[10] Frege, Gottlob, Posthumous Writings, H. Hermes and F.Kambartel, eds., Blackwell, Oxford, 1979.

[11] Geach, Peter, 'Intentional Identity', Journal of Philosophy 74 (1967); reprinted in Logic Matters, University of California Press, 1980, to the pagination of which we refer in this paper.

[12] Montague, Richard, Formal Philosophy, edited and with an introduction by R. H. Thomason, Yale University. Press, New Haven, 1974.

[13] Sellars, Wilfrid, 'Grammar and Existence: A Preface to Ontology', in Science, Perception and Reality, Routledge and Kegan Paul, London, 1963. 